Pegem Journal of Education \& Instruction, 4(2), 2014, 111-126

Pegem Eğitim ve Öğretim Dergisi, 4(2), 2014, 111-126

www.pegegog.net

\title{
The Participation of the Secondary School Students in the School Management's Decision-Making Process (A Sample Of Beypazarı District) ${ }^{*}$
}

\author{
Elif Gamze ÖZCAN ${ }^{\dagger a}$, Mehmet ŞEREN ${ }^{b}$ \\ ${ }^{a}$ Hacettepe University, Institute of Educational Sciences, Ankara/Turkey \\ ${ }^{\mathrm{b}}$ Gazi University, Faculty of Education, Ankara/Turkey
}

\section{Article Info}

DOI: $10.14527 /$ pegegog.2014.012

Article history:

Received 12 November 2013

Revised 04 March 2014

Accepted 24 March 2014

Keywords:

Participation on management,

Students' participation,

Decision-making process.

\begin{abstract}
The purpose of this study was to reflect on the opinions of secondary school students about their effects on school management's decision-making processes. In this descriptive study, comparative survey method has been used according to subpurposes which require difference tests. Population of the research was 2883 students who are having education at eight secondary schools in Beypazarı district. Purposive sampling method was used to determine the research group. This research group was 116 students who had been chosen as class representatives by their classmates. The questionnaires were taken to the schools mentioned above in 2008-2009 Academic Year's second term. Arithmetic mean, standard deviation, $\mathrm{t}$ test, Kruskal-Wallis $\mathrm{H}$ test and Mann-Whitney $U$ tests are used to analyze data. According to the findings of the research, the general state levels are found noteworthy lower than the general demand levels on decision-making processes of school management's for students. In addition to this, students emphasize that they're more effective and willing on decision-making processes when school management takes instructional decisions rather than administrative decisions. It doesn't make any significant difference of the students' gender and the grade they are educated when the effectiveness and willingness are taken into the consideration. Students, who are having education at Anatolian High Schools, specify that they are unable to affect the school management's decision making processes. Also these students demand to affect decision-making processes much more than the other types of schools' students.
\end{abstract}

\section{Introduction}

The primary objective of the organization is to create the best working environment and include people who are working for the organization to the operations of organization, management policies and other functions. In our day, employees want to express their ideas, to be effective in the results and to be active in decisions which are relate to them; briefly, they want to participate in the management of organization rather than being just an ordinary personnel. The most important reason is the increase in their cultural level and knowledge. Today, every personnel have kind of knowledge about the solution of the problems about their organization (Gümüş, 1995, pp. 381,382).

Participating in the decision process of management is the base of contemporary management. Because contemporary management is democratic and participating in decision is one of the requirements of democracy (Aytürk, 1990, p.120). This means that cooperation of superior and subordinate is vital for how the organization will be run, from which methods will be benefited and how

\footnotetext{
* This study's teacher participation size is presented as an oral presentation at the V. Congress of Educational Administration, held in Antalya, 01-02 May 2010. This study has been recognized as a Master's Thesis in Gazi University, Institute of Educational Sciences, January 2010.

${ }^{+}$Corresponding author: e.g.ozcan@hacettepe.edu.tr
} 
the success will be achieved (Başaran, 1992, p.322). In participative management, error margin is low, application is easier, the responsibility is shared and employees are happier (Aytürk, 1990, p.120). However, who is going to be responsible for the management, who is going to be affected after the decision and what kind of effect will it be, how appropriate the distribution of task is must under any circumstances be guaranteed and all this elements should be included in the decision. Otherwise, the decision which is taken will not be effective. The decision which is not put into practice is not a valid decision; it is just a good intention (Drucker, 2006, p.49).

The role of subordinates during the process of decision depends on the attitude of manager. If a manager thinks some of the subordinates can be a rival of him/her in the future, they may not give them right to participate in the decision process (Bursalığlu, 2005, pp. 94,95). Even if the manager has no such intention and even the content of the decision includes programs in favor of the employees, excluding employees during the decision process may be necessary in order to prevent the rising of effect which is expected from the decision. Because personnel thinks it is a favor rather than earned right (Eren, 1989, p.416). Environment of confident should be guaranteed; otherwise, desired result cannot be achieved (Aydın, 2000, p.285).

Managers of organizations get together mainly for putting the decisions on employees not consulting them. In these meetings, the offers of the managers are discussed and subordinates are channeled towards supporting these offers. Since what are the problems and what can be the proper solutions for these problems are determined by the managers, the decision will be as the managers want (Onaran, 1971, p.179). If employees are bestowed to participation right, this must be done sincerely with full intention. Sometimes, managers already make their decisions but they pretend they need the ideas of employees; this insincerity will be understood clearly by the employees (Baykal, 1978, p.30).

If managers allow employees to participate in the decision processes which are related to their organization, employees will think of "working together", not "working for someone". Shared opinions are easy to put into practice and the idea of "us" is a strong motivation for both employees and managers (Eren, 1989, p.417). Consequently, including the employees to the managing process neither takes the power from the managers, nor it is a managing trap for employees; and it is important to clarify that it is not a magical way to solve all the problems (Peker, 1995, p.121).

There is two kind of management type in school management which is autocratic and democratic. In autocratic management, everything is carried out with orders and these orders are performed without delay; the orders of the manager are not considered wrong and even if they are wrong nobody say it aloud. However, in schools everything must be arranged to improve the academic level of the students (Binbaşığlu, 1988, p.126). According to the Bilgin's (1990) research called "The effect of participating in management to the productivity", participating in management is just a symbolic in Turkish Republic. The main reason is insufficiency and sudden and unexpected orders and applications.

As creating a tradition that aims productivity within the organization will help the organization develop, the management should make assessments in the subjects in which the members of the organization are interested. Shareholders feel themselves responsible at the every phase of the process when the resolutions are applied. They use all of their energy in order not to make mistakes with the aim of procuring the perfection. The data Fişek (1977) has found about attending the administration in 16 public enterprises support this thesis. It has been found out that agreeing the ideas procures the convenience; they put an end to inconsistency and failure and it provides productive working.

There are many works that study agreeing the decisions on the basis of teachers in the education institutions. While the findings of Açıkgöz (1984), Bilgin (1996), Aldemir (1996), Yılmaz (2005), Parlar (2005), Gürkan (2006), Aksay and Ural (2008) impress that the attending of the people who are affected by the decisions will be beneficial for the organization, it will be realized that employees don't agree in terms of their expectations. 
The fact that education needs diversify day by day is also same in the process of taking decisions regarding the schools. Students who are directly affected by everything are sufficient in putting their ideas forward. Unfortunately, students are not able to put their ideas forward even at the level of higher education. According to the study of Dündar (2013), students at the level of higher education express their ideas and this is performed by establishing student councils in Turkey, but this action is not sufficient in students' attendance in the decisions.

One of the resolutions taken in the $4^{\text {th }}$ National Education Council (1949) was related with the attendance of the students and the teacher in the decisions taken in the schools and its necessity; Students should have meetings with the teachers and administrators in a friendly manner and take decisions by discussing between each other accordingly. They could also found student institutions if they think it's necessary and will go to the polls for the collective services.

In recent years, student Councils have been founded in many countries with the aim of increasing the student attendance and activating the democracy education. This constitution which started in universities has been degraded to primary and secondary education. Ministry of National Education has drawn attention with the Regulation of Democracy Education in Schools and School Councils (2004). With the National Education Fundamental Law no. 1739 (1973), this regulation related with the convention of UN Child Right and European Conventions of child right includes the way of electing and being elected of the representatives of class, school, districts and cities. In other words, it gets stuck with the method rather than including the importance of the effect related with the attendance of students.

It needs to be described how the process of decision making in schools goes for satisfying the current education needs of the society and the ideas of the students in this context need to be put forward. Almost all of the sources related with the attending to the decisions are at the dimension of teacher and they are complementary. However, there are not sufficient sources that will enlighten the situation of students' attending/joining the decisions.

The purpose of this study is to reflect on the opinions of secondary school students about their effects on school management's decision-making processes. To do this, the main purpose has been divided into five extended sub-purposes. These sub-purposes aims to find if:

1) There is a significant difference between students' participation perceptions and requests in decision making process.

2) There is a significant difference between students' participation perceptions about instructional and administrative dimensions in decision making process.

3) There is a significant a difference between the requests of the students' participation in instructional and administrative dimensions of decision making process.

4) There is a significant difference between the perceptions of the students about the participation level depending on their personal variables.

5) There is a significant difference between the students' participation requests related on their personal variables.

\section{Method}

\section{Research Design}

This research is a descriptive survey model related with the students' attendance to the decisions and their expectations of joining the administration. According to Karasar (2000), descriptive model is an approach of researching that aims describing a current situation in the way it is. 
In this descriptive study, comparative survey method has been used according to sub-purposes which require difference tests.

\section{Participants}

Population of the research was 2883 students who are having education at eight secondary schools in Beypazarı district. The research sample was 116 students who had been chosen as class representatives by their classmates. Accordingly purposive sampling method was used to determine the research group. According to Sencer (1989) purposive sampling method is to observe the most appropriate section of the universe.

\section{Instrument}

In the research, the Turkish edition of Lipham's (1973) "Decision Involvement Analysis" questionnaire, adapted to Turkish by Açıkgöz (1984) as "Karara Katılma Anketi", has been used. This questionnaire had twenty three headings of decision making about teachers' opinions. Seven unsuitable headings were eliminated to provide the consistency based on the opinions of a small number of students. The survey which includes the remaining 16 decision topics has been carried out in this way. These 16 topics have been sorted bottom to the top under the title "Decision Topic". There are two dimensions opposing these which are in the original scale. And two questions have been asked to determine educational and managerial aspects and participation and expectation about decision process. Four point likert scales have been used under each question including never (1) too little (2) some (3) too much (4) options.

In this study, two dimensions in decision participation survey , "Educational" and "Managerial", have been taken as they are but when consulted to the experts, it has been decided that the item number 05 which has been actually in educational decision topics should be involved in managerial decision topics. Distribution of decision topics in educational and managerial areas and orders in the survey are like this:

\section{$\underline{\text { Item no }}$ Educational Decision Topics}

01 Developing the ways of informing parents about the situation of students

02 Deciding how to evaluate students' success

12 Choosing course book and other educational materials

13 Determining the grading rules

14 Determining the education and examination method in lessons

15 Benefiting from the environmental opportunities to teach the lessons more effectively

\section{Item no Managerial Decision Topics}

03 Creating and implementing a sense of discipline at school

$04 \quad$ Planning student consultancy studies at school

$05 \quad$ Making the income and expense plan of school

$06 \quad$ Planning time table of school

07 Solving the problems showing up in school-environment relations

08 Determining and reviewing the targets of your school

09 Determining the principles of evaluating the teachers

10 Planning obtainment, protection and usage of information (mental file etc.) about the student

11 Preparing weekly course schedule

16 Evaluating the functioning of school 


\section{Data Analysis}

After all data has been obtained, Cronbach Alpha test which is known as internal consistency calculation as well has been applied in order to evaluate the credibility of the calculations extracted from 16 topics. Cronbach Alpha point is .91 for perceptions of participating in decision and .88 for the will to participate. Validity calculations of the scales have been obtained from factor analysis. When calculation is made for 16 topics with decision evaluation using decision participation data, total variance which has been explained with measurements obtained from this scale instrument is $\% 52$. When 16 topics are evaluated for participation data, total explained variance is \%59 with the measurements obtained with this instrument.

The questionnaire has been taken to the schools mentioned above in 2008-2009 Academic Year's second term. Arithmetic mean, standard deviation, $\mathrm{t}$ test, Kruskal-Wallis $\mathrm{H}$ test and Mann-Whitney $\mathrm{U}$ tests are used to analyze data. Significance level is taken as $p<.05$ for difference analyses.

\section{Results}

According to the findings of the research, the general state levels are found noteworthy lower than the general demand levels on decision-making processes of school management's for students. In addition to this, students emphasize that they're more effective and willing on decision-making processes when school management takes instructional decisions rather than administrative decisions. It doesn't make any significant difference of the students' gender and the grade they are educated when the effectiveness and willingness are taken into the consideration.

Students, who are having education at Anatolian High Schools, specify that they are unable to affect the school management's decision making processes. Also these students demand to affect decisionmaking processes much more than the other types of schools' students.

\section{Discussion, Conclusion \& Implementation}

A person in a managerial position is someone who doesn't command but leads people with his/her knowledge of management (Drucker, 1994, pp.84-85). Some concepts like cooperation, mutual thinking, team work, belonging and strategic planning came into prominence as new necessities in managerial field in 1990s. (Parks \& Barrett, 1994,p.11).

Today, establishing School Development Management Team (SDMT) which was known as total quality management previously and making and implementing strategic planning are the new responsibilities of school principals. And this shows how this change affects schools. Besides, involvement of the students in school management was made obligatory with Regulation of Democracy Education in Schools and School Councils (2004). Thus, the important thing is to research not why participation is important at school but why it cannot be maintained. Participation in decision-making process is an essential part of public life including schools. The decisions made by the school management have a big impact over the people. Each member's qualifications and interests should be taken into consideration by the principals in order to increase the participation rate at schools. Students; the most essential parts of the schools, are directly affected from the educational process. Hence their ideas about the educational needs must be taken into account as important demands.

In conclusion, especially for Anatolian High School students, student participation level was not at anticipated ratio. Anatolian High Schools' students are prepared to university exam by using a loaded curriculum. With new researches, it should be clarified in which requirements students might not find any opportunity to take part in the school management processes. To make the students more active in the participation process, necessary information about the rights and the duties must be given to 
student representatives, these students' participation abilities should be developed by their school management.

Educational process must be carefully designed in order to develop the student. Repressive manner may block the mental development of the children and devitalize them at school. Therefore, a participant management provides efficiency and enables schools to adapt the changes around them. By the help of the information and channels of communication educational processes are transformed into more transparent environments. Students are getting smarter and frequently becoming more conscious about school applications. Naturally, the students in this new era are even willing to discuss the recreation of automatically adopted and implemented disciplinary rules in schools. In order to keep up with the changes, students should be supported to participate in the decision making process.

In order to make the students who are affected by decisions taken more active in decision making process, the roles of class representatives must be more prominent. Hence, new researches should be carried out for the students who want to participate in the decision making process and the possibility of having lack of information about their rights and responsibilities should be eliminated. 


\title{
Ortaöğretim Okullarındaki Öğrencilerin Okul Yönetiminin Karar Verme Sürecine Katılımları (Beypazarı Örneği)*
}

\author{
Elif Gamze ÖZCAN ${ }^{\dagger a}$, Mehmet ŞEREN ${ }^{b}$ \\ ${ }^{a}$ Hacettepe Üniversitesi, Eğitim Bilimleri Enstitüsü, Ankara/Türkiye \\ ${ }^{\mathrm{b}}$ Gazi Üniversitesi, Eğitim Fakültesi, Ankara/Türkiye
}

\section{Makale Bilgisi}

DOI: 10.14527/pegegog.2014.012

Makale geçmişi:

Geliş 31 Aralık 2013

Düzeltme $\quad 03$ Mart 2014

Kabul 25 Mart 2014

Anahtar kelimeler:

Yönetime katılma,

Öğrencilerin katılımı,

Karar verme.

\section{Öz}

$\mathrm{Bu}$ araştırmanın amacı, ortaöğretim öğrencilerinin, okullarında kendilerini ilgilendiren konulardaki kararlara katılımlarına ve katılma isteklerine ilişkin algılarını belirlemektir. Araştırma evreni Ankara ili Beypazarı ilçesindeki sekiz ortaöğretim okulundaki 2883 öğrencidir. Okul yönetimine katılması için sınıf arkadaşları tarafından seçilen 116 sınıf temsilcisinin doğrudan bu araştırmanın hedef kitlesini temsil etmesi nedeniyle amaçı örnekleme yoluyla bu öğrencilere ulaşılmaya çalışılmıştır. 2008-2009 öğretim yılında yapılan bu betimsel araştırmada veri toplama aracı olarak Karara Katılma Anketi kullanmıştır. Veriler aritmetik ortalama, standart sapma, $\mathrm{t}$ testi, Kruskal Wallis H-Testi ve Mann - Whitney U testi teknikleri ile çözümlenmiştir. Öğrencilerin kararlara, istediklerinden düşük seviyelerde katıldıkları, öğretimsel kararlara yönetimsel kararlardan daha çok katıldıkları ve daha çok katılmayı istedikleri bulunmuştur. Sınıf ve cinsiyet değişkenleri, kararlara katılma durumlarında ve katılma isteklerinde önemli fark yaratmamaktadır. Ancak okul türü değişkeni incelendiğinde öğrencilerin kararlara katılma durumlarında anlamlı farklar ortaya çıkarmıştır. Anadolu Liseleri öğrencilerinin kararlara katılma durumları, Meslek Liseleri ile Genel Lise öğrencilerinden anlamlı ölçüde düşük çıkmıştır.

\section{Giriş}

Örgütte çalışan insanların örgütün işleyişi, yönetim politikaları ve diğer işlevlerde söz almalarını ifade eden yönetime katılma, daha iyi bir çalışma ortamı oluşturmaktadır. Günümüzde çalışanlar, sıradan bir personel olmak yerine, kendilerini ilgilendiren her türlü kararın alınmasında aktif olmak, düşüncelerini ifade etmek, sonuçlarda etkili olmak, kısaca örgütün yönetimine katılmak istemektedir. Bunun en önemli nedeni insanların kültür seviyesinin ve bilgilerinin artmasıdır. Artık her personel bulunduğu örgütte problemlerin çözümüne ilişkin az çok bilgiye sahiptir (Gümüş, 1995, ss. 381,382). Bu nedenle yönetimler; kişilerin çok yönlü uzmanlaşmalarının desteklenmesi, örgütte işbirliğine ve karşılıklı saygıya dayalı sağlıklı iletişim kanallarının oluşturulması, iç denetimin benimsetilmesi gibi uygulamaların örgütün verimliliğini arttırmada önemli etkiye sahip olduğunun farkındadır. Sayılan uygulamalar ve diğer eşgüdüm faaliyetlerinin hangi usullerle yapılacağının tüm çalışanlarca benimsenmesi, örgütte bir söz ve davranış birliği yaratır.

Her yönetim anlayışında olduğu gibi okul yönetiminde de otokratik ve demokratik olmak üzere iki tip yöneticilikten söz edilebilir. Otokratik yönetimlerde her şey emirle yapılır, emirler aksatılmadan yerine getirilir ve yöneticinin emirlerinin hatalı olabileceği düşünülmez; düşünülse bile ortaya konmaz

\footnotetext{
* Bu çalışmanın öğretmenlerin karara katılımı boyutu 01-02 Mayıs 2010 tarihlerinde Antalya'da düzenlenen V. Eğitim Yönetimi Kongresi'nde sözlü bildiri olarak sunulmuştur. Bu çalışma, Ocak 2010 tarihinde Gazi Üniversitesi Eğitim Bilimleri Enstitüsü Yüksek Lisans Tezi olarak kabul edilmiştir.

†azar: e.g.ozcan@hacettepe.edu.tr
} 
(Binbaşığlu, 1988, s.126). Yöneticinin aslında böyle bir niyeti olmasa ve hatta kararın konusu personelin çıkarlarını gözeten programlar içeriyor olsa dahi personeli, kendisini etkileyecek kararlara iştirak ettirmemek, alınan kararları uygulama noktasına kadar ondan saklamak; karardan beklenen etkinin ortaya çıkışını engeller. Çünkü personel, bu uygulamalara layık olduğu hissi yerine bu uygulamaların kendisine bir lütuf olarak sunulmuş olduğu hissine kapılırlar (Eren, 1989, s.416). Sonuçta karar sürecinde astların rolü, yöneticinin tutumuna göre değişir. Eğer yönetici astlarının bazılarının kendisiyle yarışacağından korkuyorsa, onlara karara katılma olanağı vermeyecektir (Bursalıoğlu, 2005, ss. 94,95).

Örgütlerde genellikle yöneticiler emirleri altındaki grubu karar almak için değil de alınan kararları kabul ettirmek için toplamaktadırlar. Bu toplantılarda yönetimin teklifi konuşulur ve astlar bu teklifi desteklemeye yöneltilirler. Sorunların ne olduğu ve tanımlanması, çözüm önerilerinin sunulması yönetim tarafından yapılacağı için karar yönetimin beklediği şekilde olacaktır (Onaran, 1971, s.179). Şayet elemanlara kararlara katılma hakkı tanınacaksa, onlara bu hissi vererek bunun içtenlikle ve eksiksiz olarak yerine getirilmesi gereklidir. Esasen karara varmış olduğu halde elemanları karara iştirak ettiriyormuş hissi verebilmek için yapılan hareketlerin samimiyetsizliği, elemanlar tarafından gayet kolaylıkla sezilir (Baykal, 1978, s.30). Böyle örgütler, demokratik gibi görünen ama aslında karar alma mekanizması otokratik olarak işleyen, samimiyetsizce yönetilen kurumlardır ve Aydın’a (2000) göre karara katılmada güven ortamı sağlanmadıkça katılmanın başarılı olması, istenilen sonucu vermesi beklenmemelidir (s.285). Bilgin'in (1990) "Yönetime katılmanın verimliliğe etkisi" adlı araştırmasında Türkiye'de yönetime katılma uygulamasının sembolik bir niteliğe sahip olduğu bulunmuştur. Bunun nedenini ise yetersizlik, tepeden inme kabul ve uygulamalar oluşturmaktadır.

Yönetimde karar sürecine katılma çağdaş yönetimin temelidir. Çünkü çağdaş yönetim demokratiktir, kararlara katılma da demokrasinin gereğidir (Aytürk, 1990, s.120). Bu da örgütün nasıl yönetileceğini, hangi yöntemlerin kullanılacağını, başarıya nasıl ulaşılacağını üstlerin ve astların birlikte düşünmesi demektir (Başaran, 1992, s.322). Katılımlı yöntemle alınan kararlarda hata payı az, uygulama kolay ve sağlam olur, sorumluluk paylaşılır, çalışanlar daha mutlu olur (Aytürk, 1990, s.120). Ancak bu şekilde çalışmaya alışık olmayan yönetimler için bu gibi çalışmalar astlarla iletişim gerektiren ve bu nedenle fazlasıyla zaman alacak eylemlerdir.

Gerçekten de karar alma sürecinde en zor olan adım, sorunu ve koşulları belirleyip karar vermektir. En zaman alıcı olan adım ise kararı uygulamaktır. Alınan karara eylem taahhütleri en baştan dâhil edilmelidir. Yani kararın her bir aşamasının yürütülmesinden kimlerin sorumlu olduğu, işi kimlerin yapacağı, karardan kimlerin nasıl etkileneceği, kararın; kararı uygulayacakların kapasitelerine denk düşürülmesi gibi bilgi ve uygulama özelliklerini içeren eylem taahhütleri, alınan karara dâhil edilmelidir. Aksi durumda alınan kararın etkin olamayacağı bellidir. Uygulanmayan karar, karar değildir; olsa olsa bir niyetten ibarettir (Drucker, 2006, s.49).

Yöneticiler, astlarının kendilerini ilgilendiren örgüt kararlarına katılmalarına olanak sağlarsa astlar arasında, birisi için çalışma düşüncesinin yerini birlikte çalışma düşüncesi alır. Ortak fikirlerin uygulanması daha kolaydır ve ortaya çıkan "biz" fikri kuvvetli bir özendirme unsurudur (Eren, 1989, s.417). Sonuç olarak; çalışanları yönetime katmak ne üst yöneticinin yetkisinin elinden gitmesidir, ne çalışanlar için bir yönetim tuzağıdır, ne de örgütün bütün sorunlarını çözen gizemli bir yöntemdir (Peker, 1995, s.121).

Örgüt içinde verimliliği amaçlayan bir geleneğin yaratılması örgütün gelişmesini sağlayacağından; yönetimin örgüt mensuplarını ilgili oldukları konularda değerlendirmesi gerekir. Paydaşlar, alınmasında etkili olduğu kararlar uygulamaya geçtiğinde, sürecin her aşamasında kendini sorumlu hisseder ve hataların oluşmaması için gerekirse tüm enerjisini, uygulamanın mükemmelliği için sarf eder. Bu yargıyı, Fişek'in (1977) 16 kamu kuruluşunda yönetime katılma konusunda yaptığı araştırma bulguları da desteklemektir. Zira kararlara katılımın kararlarda uygunluğu sağladığı, uyumsuzluk ve bocalamaya son verdiği, verimli çalışmayı sağladığı ortaya çıkmıştır.

Kararlara katılımın durumunu, eğitim kurumlarında öğretmen odaklı olarak araştıran birçok çalışma mevcuttur. Bunlardan Açıkgöz'ün (1984), Aksay ve Ural'ın (2008), Aldemir'in (1996), Bilgin'in (1996), 
Gürkan'ın (2006), Parlar'ın (2005) ve Yılmaz'ın (2005) bulguları, bir yandan yönetimce alınacak kararlara kararlardan etkilenen kimselerin katılımının kuruma yararlarını vurgularken; bir yandan da çalışanların, beklentileri ölçüsünde kararlara katılamadıklarını ortaya koymaktadır. Kurumun işleyişi ile ilgili kararları bu kararlardan etkilenenlerle beraber almanın önemi öğretmen odaklı olarak bu şekilde açıklanırken, okulların başlıca paydaşı olan öğrencilerin de kararlara katılımı üzerine yeterince durulması gerekir.

Eğitim yuvası olan okullarda ortamdaki her şeyin çocuğu geliştirecek şekilde düzenlenmesi gereklidir (Binbaşığlu, 1988, s.126) ve bu nedenle okullarda karara katılma çok daha önemlidir. Eğitim örgütleri daha sosyal ve toplu olup, kararların etki alanı da o derece geniştir. Eğitim sektöründeki merkezi yapılanmaya rağmen, okul yöneticilerinin kurumlarındaki süreç ile ilgili her uygulamada paydaşları ile alabileceği birçok karar alanı vardır.

IV. Milli Eğitim Şurası'nda (1949) tavsiye niteliğinde verilen kararlardan biri tüm okullardaki öğretmen ve öğrencilerin, okullarında alınan kararlara katılımlarının gerekliliği ile ilgilidir. Buna göre öğrenciler, öğretmen ve idarecilerin dostça ve devamlı nezaretleri ile toplantılar yapmalı, kendileri ile ilgili konular hakkında tartışarak, kararlar alacaklardır. Ayrıca gerek gördükleri öğrenci kurumlarını meydana getirecekler, müşterek hizmetler için seçimler de yapacaklardır.

Eğitim ihtiyaçlarının gün geçtikçe çeşitlenmesi, okullarda süreç ile ilgili alınacak kararları da çeşitlendirmektedir. Bu süreçteki her şeyden doğrudan etkilenen öğrenciler, ihtiyaçlarının ne olduğu konusunda fikir öne sürecek yeterliliktedir. Ne yazık ki yükseköğretim düzeyinde dahi öğrenciler istedikleri ölçüde kararlara katılım sağlayamamaktadır. Dündar'ın (2013) yaptığı araştırmaya göre Yükseköğretim düzeyinde öğrencilerin kararlara katılımı Türkiye'de öğrenci konseyleri kurma suretiyle yapılmakta, bu uygulama da öğrencilerin kararlara etkin katılımını sağlamaya yetmemektedir.

Son yıllarda Türkiye'de okul yönetiminde öğrenci katılımını artırmak ve demokrasi eğitimini etkinleştirmek amacıyla Okul Öğrenci Meclisleri oluşturulmaya başlanmıştır. Öncelikle üniversitelerde başlayan bu oluşum, zamanla Ortaöğretim ve İlköğretim düzeyine indirgenmiştir. Öğrencilerin yönetime katılımı konusuna Milli Eğitim Bakanlığı tarafından 2004 yılında yayınlanan Okullarda Demokrasi Eğitimi ve Okul Meclisleri Yönetmeliği ile dikkat çekilmiştir. 1739 sayılı Millî Eğitim Temel Kanunu ile bu husustaki uluslar arası politika belgeleri olan Birleşmiş Milletler Çocuk Hakları Sözleşmesi ile Çocuk Haklarının Kullanılmasına İlişkin Avrupa Sözleşmesi gereği olarak yürürlüğe konulan bu yönetmelik; sınıf, okul, ilçe ve il temsilcilerinin seçme-seçilme usulünü kapsamaktadır. Bir başka deyişle demokrasi aracı ile öğrencilerin okuldaki idari sürece katılımının, eğitimsel birtakım ihtiyaçlarını karşılamakta söz sahibi olmalarındaki etkisinin önemini içermekten ziyade usule takılmıştır.

Toplumun güncel eğitim ihtiyaçlarına yeterince cevap verebilmek açısından okullardaki karar alma sürecinin nasıl işlediğini betimlemek; bunun için de öğrenci görüşlerinin ne doğrultuda olduğunu ortaya koymak gerekmektedir. Okullarda kararlara katılma ile ilgili mevcut kaynakların neredeyse tamamı öğretmen boyutunda ve birbirini tekrarlayan niteliktedir. Bununla birlikte öğrencilerin kararlara katılımı ile ilgili durumu aydınlatacak yeterli sayıda kaynak mevcut değildir.

Bu araştırmanın amacı, ortaöğretim öğrencilerinin kendilerini ilgilendiren öğretimsel ve yönetimsel kararlara katılma durumlarına ilişkin algılarını ve katılma isteklerine ilişkin görüşlerini belirlemektir.

Bu ana amaca ulaşabilmek için belirlenen alt amaçlar şunlardır:

1) Ortaöğretim öğrencilerinin, okullarında kendilerini ilgilendiren konularla ilgili olarak alınan kararlara katılma durumları ve kararlara katılma istekleri arasında anlamlı bir fark var mıdır?

2) Öğrencilerin öğretim ve yönetim alanlarındaki kararlara katılma durumlarına ilişkin algıları arasında anlamlı fark var mıdır?

3) Öğrencilerin öğretim ve yönetim alanlarındaki kararlara katılma isteklerine ilişkin görüşleri arasında anlamlı fark var mıdır?

4) Öğrencilerin kurumlarında alınan kararlara katılma durumları, kişisel değişkenlerine (okul türü, cinsiyet ve sınıf düzeyi) göre anlamlı farklılık göstermekte midir? 
5) Öğrencilerin kurumlarında alınan kararlara katılma istekleri, kişisel değişkenlerine (okul türü, cinsiyet ve sınıf düzeyi) göre anlamlı farklılık göstermekte midir?

Eğitim sektörü içinde yer alan kurum ve kuruluşların eğitim öğretim süreçlerinin selameti açısından gerekliliğini vurguladıkları "yönetime katılma" olgusunun, hem okul yönetiminin işlerini hafifletecek, hem de öğretmen ve öğrencilerin okullarına bağıııklarını arttıracak bir önlem olması açııından bu konu ile ilgili uygulamaların takibi gereklidir. Bu araştırma, karara katılma alanında eksikliği hissedilen öğrenci boyutunu ele alması, ortaöğretim kurumlarında karara katılma olgusunun nasıl uygulama bulduğu ile ilgili güncel öğrenci görüşlerini içermesi ve bu bulgulara göre Türkiye'deki güncel eğitim yönetimi uygulamalarına dikkat çekmesi açısından önemlidir.

\section{Yöntem}

\section{Araştırma Modeli}

Bu araştırma, ortaöğretim kurumlarındaki öğrencilerin, yönetim kararlarına katılma düzeylerine ve yönetime katılma beklentilerine ilişkin algılarını belirlemeye yönelik olduğundan tarama modelinde betimsel bir çalışmadır. Karasar'a (2000) göre, tarama modeli geçmişte veya halen var olan bir durumu var olduğu şekliyle betimlemeyi amaçlayan araştırma yaklaşımıdır.

\section{Katılımcılar}

Araştırmanın evreni 2008-2009 öğretim yılında Ankara ili Beypazarı ilçesindeki sekiz ortaöğretim okulunda okuyan 2883 öğrencidir; bunlardan okul yönetimine katılması için sınıf arkadaşları tarafından seçilen sınıf temsilcilerinin çalışma grubu olarak alınması amaca uygun bulunmuştur.

Amaçlı örnekleme, araştırmanın amaçları doğrultusunda bir evrenin temsilci bir örneği yerine, amaçlı olarak bir ya da birkaç alt kesimini örnek olarak almaktır. Başka bir deyişle amaçlı örnekleme, evrenin soruna en uygun bir kesimini gözlem konusu yapmak demektir (Sencer, 1989, s.386). Buna göre 116 sınıf temsilcisi öğrenciye ulaşılmaya çalışıımıstır. Başta, üniversite sınavına hazırlanmak amacıyla okula gelmeyen 12. Sınıf öğrencileri olmak üzere sürekli devamsızlık yapan sınıf temsilcilerine ulaşılamadığından çalışma grubunun $\% 75^{\prime}$ ine tekabül eden 87 öğrenciden toplanan verilerle bulgular oluşturulmuştur.

Illçede mesleki eğitim hizmeti veren ortaöğretim okullarındaki 65 sınıf temsilcisinden 56 'sına (\%86), genel ortaöğretim okullarında okuyan 51 sınıf temsilcisinden $31^{\prime}$ ine (\%60) ulaşılmıştır. Bu durumda araştırma verilerinin \% 64'ü mesleki ortaöğretimden, \% 36'sı da Genel ortaöğretim kurumlarından elde edilmiştir.

\section{Veri Toplama Aracı}

Öğrencilerin okulda alınan ve kendilerini etkileyen kararlara ne ölçüde katıldığını ve ne ölçüde katılma beklentisi içinde olduklarını belirlemek amacıyla, aslı Lipham (1973) tarafından geliştirilmiş "Decision Involvement Analysis" adlı anketin; Açıkgöz (1984) tarafından "Karara Katılma Anketi” adıyla öğretmenler için 23 karar konusu içeren uyarlaması, bu araştırmada öğrenciler için yeniden düzenlenmiştir.

Ölçek iki bölümden oluşmuştur. Birinci bölüm öğrencilerin; okudukları okul türü, sınıfı ve cinsiyeti ile ilgili kişisel bilgileri toplayan özelliktedir. Ölçme aracının ikinci bölümü ile cevaplayıcının hem karar konularına ne kadar katılabildiklerini, hem de bu karar konularına ne kadar katılmak istediklerini belirtmeleri istenmiştir. Bu bölümde okullarda alınan kararlardan öğrencilerin daha ilgili olduğunun düşünüldüğü on altı karar konusu yer almaktadır. Ölçeğin aslında yer alan ve öğretmenlere göre düzenlenmiş yirmi üç karar konusundan hangilerinin öğrenciler ile daha yakından ilgili olduğu sorulan 
yirmi beş kişilik bir öğrenci grubunun verdiği cevaplardan yola çıkılarak hiç seçilmeyen yedi karar konusu anketten çıkartılmıştır. Geriye kalan on altı karar konusunun yer aldığı öğrenci anketi bu şekilde oluşturulmuştur. Öğretimsel ve yönetimsel işler boyutlarındaki bu on altı konu, "Karar Konusu" başlığı altında yukarıdan aşağıya doğru sıralanmış; bunların karşııına, ilgili karar sürecine mevcut katılma durumu ve katılma beklentisini belirlemek amacıyla iki soru sorulmuştur. Bu iki sorunun her birinin altında hiç (1), çok az(2), biraz(3), çok(4) cevap seçeneklerini içeren dörtlü likert ölçeği kullanılmıştır.

Tüm veriler elde edildikten sonra ölçme aracında yer alan 16 maddeden elde edilen ölçümlerin güvenilirliğini hesaplamak için, iç tutarlılık hesaplaması olarak da bilinen Cronbach Alpha testi uygulanmıştır. Öğrencilerin kararlara katılma durumlarına ilişkin algıları için Cronbach Alpha katsayısı .91; katılma istekleri için Cronbach Alpha katsayısı .88 olarak bulunmuştur. Ölçümlerin geçerlilik hesaplaması, faktör analizi yapılarak elde edilmiştir. Karara katılma durumu verileri ile 16 madde için hesaplama yapıldığında bu ölçme aracı ile elde edilen ölçümlerle toplam varyansın $\% 52$ 'sinin açıklandığı belirlenmiştir. Karara katılma istek verileri ile 16 madde için hesaplama yapıldığında ise bu ölçme aracı ile elde edilen ölçümlerle toplam varyansın \%59'unun açıklandığı belirlenmiştir.

Karara katılma anketindeki "Öğretimsel" ve "Yönetimsel" olmak üzere gruplanan 2 boyutu bu çalışmada olduğu gibi alınmış ancak uzmanlara danışıldığında ölçeğin aslında öğretimsel karar konuları içinde yer almış olan 05 sıra numaralı maddenin, yönetimsel karar konuları içinde yer almasının daha uygun olduğuna karar verilmiştir. Karar konularının öğretim ve yönetim alanlarına dağılımı ve ankette yer alışs sıraları şöyledir:

\section{Sıra no Öğretimsel karar konuları}

01 Ana babalara öğrencilerin durumlarının bildirme yollarının geliştirilmesi

02 Öğrencilerin başarılarının nasıl değerlendirileceğine karar verilmesi

12 Ders kitabı ve öteki öğretim materyallerinin seçilmesi

13 Not verme kurallarının belirlenmesi

14 Derslerde izlenecek öğretim ve sınav yönteminin belirlenmesi

15 Dersleri daha etkili işleyebilmek için çevre olanaklarından yararlanılması

$\underline{\text { Sıra no Yönetimsel karar konuları }}$

03 Okulunuzdaki disiplin anlayışının oluşturulması ve uygulamaya konması

04 Okulunuzdaki öğrenci danışmanlığı çalışmalarının planlanması

05 Okulunuzun gelir ve harcamalarının planlanması

06 Ders dağııımının yapııması

07 Okul-çevre ilişkilerinde beliren sorunların çözülmesi

08 Okulunuzun hedeflerinin belirlenmesi ve gözden geçirilmesi

09 Öğretmenlerin değerlendirilmesinde uyulacak esasların belirlenmesi

10 Öğrenciye ilişkin bilgilerin elde edilmesi, korunması ve kullanılmasının planlanması

11 Haftalık ders programlarının hazırlanması

16 Okulunuzun işleyişinin değerlendirilmesi

\section{Verilerin Toplanması}

Araştırma verileri 2008-2009 öğretim yılında Ankara ili Beypazarı ilçesindeki sekiz ortaöğretim okulunda okuyan 2883 öğrenciyi temsilen okul yönetimine katılması için sınıf arkadaşları tarafından seçilen 116 sınıf temsilcilerinden, ulaşılabilen 87'sinden toplanmıştır.

\section{Verilerin Analizi}

Araştırmaya ilişkin verilerin istatistiksel analizi SPSS 10.00 paket programı kullanılarak yapılmıştır. Aynı grubun farklı iki soruya verdikleri cevapların aritmetik ortalamaları karşılaştıııldı̆ından, gruptan elde edilen veriler normal dağıım gösterdiğinden ve varyanslar arasındaki fark 0.05 değerinden yüksek 
yani homojen çıktığından; öğrencilerin kararlara katılma durumları ile kararlara katılma istekleri, öğretimsel ile yönetimsel boyutlardaki kararlara katılma durumları ve katılma istekleri arasında fark olup olmadığını belirlemek amacıyla eşleştirilmiş gruplar t testi tekniği kullanılmıştır. İki alt kategorisi olan "cinsiyet" değişkenine göre bağımlı değişkenlerin puan ortalamaları arasındaki farkı belirlemek için bağımsız gruplar t testi tekniği kullanılmıştır. İkiden çok kategorisi olan "okul türü" ve "sınıf düzeyi" bağımsız değişkenlerinin bağımlı değişkenlere etkisini belirlemek amacıyla okullar arasındaki öğrenci temsilcisi sayılarındaki farklılığın büyük olmasından dolayı non-parametrik testlerden Kruskal Wallis $\mathrm{H}$ Testi ile farkların kaynağını bulmak için Mann- Whitney $U$ testi kullanılmıştır. Grupların karşılaştırılmasında anlamlılık düzeyi $p \leq .05$ olarak belirlenmiştir.

\section{Bulgular}

Öğrencilerin okullarında alınan kararlara katılma durumlarına ilişkin algıları ile katılma isteklerine ilişkin görüşleri arasında anlamlı farklılık olup olmadığını araştıran birinci alt amaçla ilgili bulgulara göre; Öğrencilerin okullarda alınan kararlara katılma düzeyleri istedikleri seviyeden anlamlı derecede farklı olup, daha az düzeydedir. Öğrencilerin geneli, kararlara düşük seviyelerde katıldıklarını, yüksek seviyelerde katılmak istediklerini belirtmişlerdir.

Tablo 1.

Öğrencilerin Kararlara Katılma Durumlarına ve Katılma Isteklerine ilişskin t-Testi Bulguları.

\begin{tabular}{lccccc}
\hline Öğrenci görüşleri & $\overline{\boldsymbol{x}}$ & $\mathbf{S}$ & $\mathbf{S d}$ & $\mathbf{t}$ & $\mathbf{p}$ \\
\hline Katılma durumları & 2.64 & .76 & 86 & 4.79 & $.000^{*}$ \\
Katılma istekleri & 3.06 & .59 & & & \\
\hline
\end{tabular}

$* p<.05$

Tablo 1'deki aritmetik ortalama değerleri arasındaki fark testi hesaplamalarına göre öğrencilerin okullarında alınan kararlara katılma durumları, katılmak istedikleri seviyeden anlamlı derecede farklı olup, daha az düzeydedir [t(86)=4.79, p <.05]. Bu bulgu, Dündar'ın (2013) Yükseköğretim öğrencileri ile yaptığı araştırma bulguları ile aynı doğrultudadır.

Tablo 2.

Öğrencilerin Öğretimsel ve Yönetimsel Boyutlarda Kararlara Katılma Durumlarına Illişkin t-Testi Bulguları.

\begin{tabular}{lccccc}
\hline Boyutlar & $\overline{\boldsymbol{x}}$ & $\mathbf{S}$ & $\mathbf{S d}$ & $\mathbf{t}$ & $\mathbf{p}$ \\
\hline Öğretimsel & 2.72 & .774 & 86 & 2.38 & $.019^{*}$ \\
Yönetimsel & 2.60 & .782 & & & \\
\hline
\end{tabular}

$* p<.05$

Tablo 2'deki aritmetik ortalama değerleri arasındaki fark testi hesaplamalarına göre öğrencilerin okullarında alınan kararlara katılma durumları, kararın öğretimsel ya da yönetimsel boyutta oluşu ile anlamlı farklılık göstermektedir $[\mathrm{t}(86)=2.38, \mathrm{p}<.05]$.

Öğrencilerin öğretimsel boyutta alınan kararlara katılma durumları için $\bar{x}=2.72$ şeklindeki aritmetik ortalama değerinin, elde edilen $\mathrm{p}$ değerine bakılarak; yönetimsel boyutta alınan kararlara katılma durumu için $\bar{x}=2.60$ şeklindeki aritmetik ortalama değerinden farklı olduğu bulunmuştur. Bu bulgular, öğrencilerin dersleriyle doğrudan ilişkili olan öğretimsel boyuttaki karar konularında kendilerini yönetimsel konulara göre daha yeterli hissetmekte olduğunu göstermektedir.

Tablo 3'deki aritmetik ortalama değerleri arasındaki fark testi hesaplamalarına göre öğrencilerin okullarında alınan kararlara katılma istekleri, kararın öğretimsel ya da yönetimsel boyutta oluşu ile anlamlı farklılık göstermektedir $[\mathrm{t}(86)=5.23, \mathrm{p}<.05]$. 
Tablo 3.

Öğrencilerin Öğretimsel ve Yönetimsel Boyutlarda Kararlara Katılma Isteklerine Ilişkin t-Testi Bulguları.

\begin{tabular}{lccccc}
\hline Boyutlar & $\overline{\boldsymbol{x}}$ & $\mathbf{S}$ & Sd & $\mathbf{t}$ & $\mathbf{p}$ \\
\hline Öğretimsel & 3.20 & .624 & 86 & 5.23 & $.000^{*}$ \\
Yönetimsel & 2.97 & .632 & & & \\
\hline$* \mathrm{p}<.05$ & & & & &
\end{tabular}

Elde edilen $\mathrm{p}$ değerine bakılarak öğrencilerin öğretimsel boyutta alınan kararlara katılma istekleri için $\bar{x}=2.97$ şeklindeki aritmetik ortalama değerinin yönetimsel boyutta alınan kararlara katılma istekleri için $\bar{x}=3.20$ aritmetik ortalamasından farklı olduğu bulunmuştur. Bu bulgulara göre öğrencilerin, dersleriyle doğrudan ilişkili olan öğretimsel boyuttaki karar konularına, yönetimsel karar konularından daha çok katılmak istediği ortaya çıkmıştır.

Öğrencilerin öğretim ve yönetim boyutlarında alınan kararlara katılım durumları ve katılma istekleri arasında farklılık olup olmadığını araştıran ikinci ve üçüncü alt amaçlarla ilgili bulgulara göre; Alınan kararın öğretimsel ya da yönetimsel boyutta oluşu öğrencilerin kararlara katılma durumlarını ve kararlara katılma beklentilerine ilişkin algıları üzerinde fark yaratmaktadır. Öğrenciler öğretimsel boyuttaki kararlara yönetimsel boyuttaki kararlardan daha çok katılmakta ve daha çok katılmayı istemektedirler.

Öğrencilerin kararlara katılma durumlarının kişisel değişkenlerine göre değişip değişmediğini araştıran dördüncü alt amaçla ilgili bulgulara göre; cinsiyet değişkeni ile sınıf düzeyi değişkeni, kararlara katılma durumlarında önemli farklılık yaratmamaktadır. Ancak okul türü değişkeni, bağımlı değişkenler üzerinde anlamlı fark yaratmaktadır.

Öğrencilerin okudukları okul türünün farklı olmasının, okullarında alınan kararlara katılma durumlarına ilişkin algı düzeyleri üzerinde farklılık oluşturup oluşturmadığını belirlemek için yapılan Kruskal- Wallis $\mathrm{H}$ testi sonuçları tablo 4 'te verilmiştir.

Tablo 4.

Öğrencilerin Okullarında Alınan Kararlara Katılma Durumlarına ilişkin Algılarının Okudukları Okulun Türüne Göre Kruskal-Wallis H Testi Sonuçları.

\begin{tabular}{lccccc}
\hline Okudukları Okul Türü & $\mathbf{n}$ & Sıra Ort. & sd & $\mathbf{x}^{2}$ & $\mathbf{p}$ \\
\hline Meslek Liseleri & 56 & 46.67 & 2 & 20.69 & $.000^{*}$ \\
Genel Lise & 12 & 64.00 & & & \\
Anadolu Liseleri & 19 & 23.50 & & & \\
\hline${ }^{*} \mathrm{p}<.05$ & & & & &
\end{tabular}

Tablo 4'de Kruskal-Wallis H testi sonucuna göre öğrencilerin okudukları okul türünün farklı olması, okullarında alınan kararlara katılma durumlarına ilişkin algı düzeyleri üzerinde anlamlı farklılık yaratmaktadır $\left[\mathrm{x}_{(2)}^{2}=20.69, \mathrm{p}<.05\right]$. Okul türlerinin sıra ortalamaları dikkate alındığında okullarında alınan kararlara katılma durumlarına ilişkin algı düzeyleri en yüksek Genel lise öğrencilerinde, daha sonra Meslek lisesi öğrencilerinde, en düşük ise Anadolu türü liselerde okuyan öğrencilerde olduğu ortaya çıkmıştır.

Gruplar arasındaki farklılığın hangi gruplardan kaynaklandığını belirlemek üzere okul türleri birbirleri ile Mann-Whitney U testi kullanılarak karşılaştırılmış; bu ikili karşılaştırmaların sonuçları Tablo 5'de verilmiştir. 
Tablo 5.

Öğrencilerin Okudukları Okulun Türüne Göre Okullarında Alınan Kararlara Katılma Durumlarına Ilişkin Ortalamaları Arasındaki Farkın Kaynağını Gösteren Mann-Whitney U Testi Sonuçları.

\begin{tabular}{lccccc}
\hline Okul Türü & $\mathbf{n}$ & Sıra Ort. & Sıra Top. & $\mathbf{U}$ & $\mathbf{p}$ \\
\hline Meslek Liseleri & 56 & 31.88 & 1785.50 & 189.50 & $.018^{*}$ \\
Genel Lise & 12 & 46.71 & 560.50 & & \\
\hline Meslek Liseleri & 56 & 43.29 & 2424.00 & 236.00 & $.000^{*}$ \\
Anadolu Liseleri & 19 & 22.42 & 426.00 & & \\
\hline Genel Lise & 12 & 23.79 & 285.50 & 20.50 & $.000^{*}$ \\
Anadolu Liseleri & 19 & 11.08 & 210.50 & & \\
\hline${ }^{*} \mathrm{p}<.05$ & & & & &
\end{tabular}

Gruplar arası farkları bulmak için yapılan sıra analizlerine göre okunan lisenin türü, öğrencilerin kararlara katılma durumlarına ilişkin algılarını anlamlı bir şekilde değiştirmektedir. Genel Lise öğrencileri okullarında kendileri ile ilgili alınan kararlara Meslek Lisesi öğrencilerinden daha yüksek düzeyde katılmaktadırlar (U=189.50, p<.05). Meslek Lisesi öğrencileri okullarında kendileri ile ilgili alınan kararlara Anadolu Lisesi öğrencilerinden daha yüksek düzeyde katılmaktadırlar (U=236.00, $p<.05)$. Genel Lise öğrencileri okullarında kendileri ile ilgili alınan kararlara Anadolu Lisesi öğrencilerinden daha yüksek düzeyde katılmaktadırlar (U=20.50, p<.05).

Okulların fiziki şartları düşünüldüğünde tam tersi bir durum beklenirken, Anadolu türü liselerin öğrencilerinin okullarında alınan kararlara düşük düzeylerde katıldıklarını düşündükleri, buna karşın Meslek Liseleri ile Genel Lise öğrencilerinin yüksek düzeylerde katılma fırsatı buldukları ortaya çıkmıştır.

Aritmetik ortalaması düşük aralıklarda çıkan Anadolu türü liselerde okuyan öğrencilerin okullarında alınan kararlara katılım durumları; aritmetik ortalamaları yüksek düzeylerde olan Meslek Lisesi ve Genel Lise türü okullarda okuyan öğrencilerin okullarında alınan kararlara katılma durumlarına göre anlamlı düzeyde düşük çıktığı, sıra ortalamaları fark verileri ile desteklenmiştir. Bu bulgu, Meslek Liseleri ile Genel Lise türü okullara göre öğrencilerin okumayı öncelikle tercih ettikleri Anadolu türü liselerde öğrenci katılımına verilen önemin Meslek Lisesi ile Genel Lise gibi diğer tür ortaöğretim okullarına göre daha düşük olduğunu gösterdiğinden önemlidir.

Öğrencilerin kişisel değişkenlerinin kararlara katılma isteklerinde etkili olup olmadığı araştırılan beşinci alt amaçla ilgili bulgulara göre; okul türü, cinsiyet ve sınıf düzeyi değişkenleri, kararlara katılma isteklerinde önemli farklılık yaratmamaktadır.

\section{Sonuç, Tartışma ve Öneriler}

Bu araştırma ile öğrencilerin kararlara, istediklerinden düşük seviyelerde katıldıkları, öğretimsel kararlara yönetimsel kararlardan daha çok katıldıkları ve daha çok katılmayı istedikleri bulunmuştur. Sınıf ve cinsiyet değişkenleri, kararlara katılma durumlarında ve katılma isteklerinde önemli fark yaratmamaktadır. Ancak okul türü değişkeni öğrencilerin kararlara katılma durumlarında anlamlı farklar ortaya çıkarmıştır. Anadolu Liseleri öğrencilerinin kararlara katılma durumları, Meslek Liseleri ile Genel Lise öğrencilerinden anlamlı ölçüde düşük çıkmıştır.

Okulların demokratikleşmesi için hem okul idarecilerinin hem de öğretmenler ile öğrencilerin bu konuda bilgili ve istekli olması gereklidir. Oysa yapılan bu araştırmadan çıkarılabilecek sonuç; öğrencilerin karara katılma süreçlerinden uzak durmakta ya da uzak tutulmakta olduklarıdır. Yönetici, karar almadan önce öğrencilere o konudaki fikirlerini sorarsa öğrencilerin gözünde idari gücünün azalacağını düşünebilir. Öğrencilerle gereğinden fazla samimi olacağını, öğrencilerin artık okul idaresinden korkmayacağını ve disiplin sorunları yaşanacağını düşünebilirler. Bilgi çağı olarak adlandırılan günümüzde idarecilerin odalarında oturup öğrenciden saklanması, belgelere imza atması ve törenlerde 
öğrencilerin topluca taltifi veya uyarılması; okul yönetme işi için yeterli gelmemektedir. E-okul, MEBBis gibi geçmişi son on yıldan önceye gitmeyen ve bu nedenle farklı yöntemler uygulamayı gerektiren yeni bilgi işleme sorumlulukları okul idarelerini öğrencilerini daha yakından tanımaya zorlamaktadır. Sürekli yeni bilgi üretimi, bunların hızla dağılması ve tüketimi, eğitim sisteminin öncelikli etkilenicisi durumundaki öğrencileri eskisinden daha uyanık hale getirmiştir. Öğrenciler bilgileri ezberlemeyi değil güncel bilgilere ulaşmayı ve kullanmayı istediklerini fark etmişlerdir. Doğal olarak eskiden ezbere kabul edilen ve uygulanan disiplin kurallarını dahi tartışarak yeniden oluşturmayı istemektedirler.

Drucker, Kapitalist Ötesi Toplum adlı kitabında yönetim alanındaki anlayış değişimini şu şekilde anlatmıştır; íkinci dünya savaşı sonuna kadar yönetici, astların işinden sorumlu kimse yani "patron" idi. Yönetim ise bir mevki, bir "güç"tü. 1950'lerden sonra yönetim, insanların performansından doğan sorumluluk olarak ifade edilirken günümüzde yönetici bilginin uygulanmasından ve insanların performansından sorumludur. Çağdaş kuruluşlarda her birimin önemi astlıkla üstlükle değil ortak amaca olan katkısıyla ilgilidir. Yönetici konumundaki kimse de emir veren değil yönetim uzmanlığı bilgisiyle yönlendiren kişidir (Drucker, 1994, ss.84-85). 1990'larda yönetim alanında yeni gereksinimler olarak, işbirliği, ortak düşünme, ekip çalışması, katılımcılık, ait olma, stratejik planlama gibi kavramlar ön plana çıkmıştır (Parks ve Barrett,1994, s.11).

Günümüzde önce toplam kalite yönetimi adıyla duyulan sonra da Okul Gelişim Yönetim Ekibi (OGYE) kurulması ve stratejik planların oluşturularak uygulanması işlerinin okul müdürlerine yeni görevler olarak yüklenmesi de bu değişimin okullara yansımasıdır. Ayrıca okulda öğrencilerin okul yönetimine katılması, Demokrasi Eğitimi ve Okul Meclisleri Yönergesi (2004) ile zorunlu hale gelmiştir. Bu nedenlerle artık okullarda katııımcılığın neden gerekli olduğunun değil, neden yeterince sağlanamadığııı araştırılmasına geçilmelidir. Alınan kararlardan etkilenen öğrencileri karar alma süreçlerinde daha etkin kılmak için sınıf temsilcilerinin rolleri görüntüden öteye götürülmelidir; bunun için kararlara katılmayı çok istediklerini belirten öğrencilerin, hakları ve görevleriyle ilgili bilgi yetersizliği yaşama olasılığının da yeni araştırmalar yapılarak değerlendirilmesi ve önüne geçilmesi gerekir. Bundan sonraki araştırmalarda yönetime katılmama durumuna neden olabilecek öğrencilerden kaynaklı sıkıntıların neler olduğunun araştırılması önerilmektedir.

Illk kez bu araştırma ile özellikle Anadolu türü liselerin öğrencilerinin karar verme süreçlerine istedikleri düzeyin altında katıldığı olduğu ortaya çıkmışır. Bu araştırmada Anadolu türü liselerin karşılaştıııldığı Genel lise ve Meslek liselerinden ayrıldığı belirgin noktalar; öğrencilerini seçme sınavı ile kaydetmesi ve daha akademik bir program uygulamasıdır. Bu araştırma ile Anadolu türü liselerde kararlara istenen ölçüde katılamama durumunun en üst düzeyde ortaya çıkmasının nedeni olarak ders yoğunluğu, okul idaresinin tutumu vb. faktörler ileri sürülebilir. Ancak tahminden ileri gidebilmek için, bunlar ve hesaba katılabilecek diğer hangi faktörlerin öğrencilerin kararlara katılma durumlarını hangi açıdan düşürdüğü yeni araştırmalar yapılarak araştııılmalıdır.

Öğrencilerin okullarında kendilerini ilgilendiren konularda katıım düzeylerini artııabilmek için sorun ve önlem tespitini amaçlayan yeni araştırmalar yapılması yönetim süreçlerinin daha ilk basamağı olan karar verme aşamasındaki eksikliklerin düzeltilmesi için önemlidir.

\section{Kaynakça}

Açıkgöz, K. (1984). Öğretmenlerin okuldaki kararlara katılımı. Unpublished doctoral dissertation, Hacettepe University, Ankara, Turkey.

Aksay, O. \& Ural, A. (2008). Ortaöğretim öğretmenlerinin okulla ilgili kararlara katılımı. Türk Eğitim Bilimleri Dergisi, 6(3), 433-460.

Aldemir, G. (1996). Öğretmenlerin okul yönetimine katılma düzeyleri (Altındağ örneği). Unpublished master's thesis, Gazi University, Ankara, Turkey.

Aydın, M. (2000). Eğitim yönetimi. Ankara: Hatiboğlu Yayınevi. 
Elif Gamze ÖZCAN ve Mehmet ŞEREN - Pegem Eğitim ve Öğretim Dergisi, 4(2) 2014, 111-126

Aytürk, N. (1990). Yönetim sanatı. Ankara: Emel Matbaacılık.

Başaran, I.E. (1992). Yönetimde insan ilişkileri. Ankara: Kadıŏ̆lu Matbaası.

Baykal, B. (1978). Motivasyon kavramına genel bakış. İstanbul: Divan Matbaacılık.

Bilgin, K.N. (1990). Yönetime katılmanın verimliliğe etkisi. Unpublished master's thesis, Gazi University, Ankara, Turkey.

Bilgin, T.F. (1996). Zonguldak merkez ilköğretim okullarındaki öğretmenlerin okul yönetimlerince alınan kararlara katılabilme derecelerinin değerlendirilmesi. Unpublished master's thesis, Gazi University, Ankara, Turkey.

Binbaşıŏ̆lu, C. (1988). Eğitim yöneticiliği. Ankara: Binbaşığlu Yayınevi.

Bursalıoğlu, Z. (2005) Okul yönetiminde yeni yapı ve davranış. Ankara: PegemA Yayıncılık.

Drucker, P.F. (1994). Kapitalist ötesi toplum, (B. Çorakçı, Trans.) İstanbul: İnkılap Kitapevi. (Original work published 1993)

Drucker, P.F. (2006). Klasik Drucker, (Z. Dicleli, Trans.) İstanbul: Bahçeşehir Üniversitesi Yayınları. (Original work published 2006)

Dündar, S. (2013). Demokratik okulun bir unsuru olarak öğrencilerin karar süreçlerine katılımı. Kuram ve Uygulamada Eğitim Bilimleri, 13(2), 853-875.

Eren, E. (1989). Yönetim psikolojisi. İstanbul: İstanbul İşletme İktisadı Enstitüsü Yayını.

Fişek, K. (1975). Yönetim. Ankara: Ankara Üniversitesi Basımevi.

Gümüş, M. (1995). Yönetimde başarı için altın kurallar. İstanbul: Alfa Basım Yayım Dağıtım.

Gürkan, M. (2007). Mesleki ve teknik eğitim kurumlarında görev yapan öğretmenlerin karara katılma durumları. Unpublished master's thesis, Yıldız Teknik University, Istanbul, Turkey.

Karasar, N. (2000). Bilimsel Araştırma Yöntemleri. Ankara: Nobel Yayın Dağıtım.

Milli Eğitim Bakanlığı. (1973). Milli Eğitim Temel Kanunu. Retrieved December 14, 2009, from http://mevzuat.meb.gov.tr/html/88.html

Milli Eğitim Bakanlığı. (2004). Okullarda demokrasi eğitimi ve okul meclisleri yönergesi. Tebliğler Dergisi. Eylül/2564.

Milli Eğitim Bakanlığı. (2009). Ankara ili istatistiki bilgileri. Retrieved December 14, 2009, from http://ankara.meb.gov.tr/sistem

Onaran, O. (1971). Örgütlerde karar verme. Ankara: Sevinç Matbaası.

Parks,D. \& Barrett, T. (1994). Principals as leaders of leaders. Pricipal. November Vol.74, No:2,11-12.

Parlar, L. (2005). Çevre faktörünün okul yönetiminin karar verme sürecine etkisi. Unpublished master's thesis, Gazi University, Ankara, Turkey.

Peker, Ö. (1995). Yönetimi geliştirmenin sürekliliği. Ankara: TODAiE Yayınları.

Sencer, M. (1989). Toplumbilimlerinde yöntem. İstanbul: Beta Basım.

Yılmaz, N. (2005). Ilköğretim kurumlarında görev yapan öğretmenlerin okul yönetimine katılma düzeyleri, Ankara ili örneği, Unpublished master's thesis, Gazi University, Ankara, Turkey.

Milli Eğitim Şurası. (1949). Retrieved December 14, 2009, from http://ttkb.meb.gov.tr/secmeler/sura/4_sura.pdf 